\title{
Article \\ L-Cysteine as an Irreversible Inhibitor of the Peroxidase-Mimic Catalytic Activity of 2-Dimensional Ni-Based Nanozymes
}

\author{
Piyumi Dinusha Liyanage ${ }^{\dagger}$, Pabudi Weerathunge ${ }^{\dagger}$, Mandeep Singh ${ }^{\dagger}$, Vipul Bansal ${ }^{*}$ and Rajesh Ramanathan * \\ Ian Potter NanoBioSensing Facility, NanoBiotechnology Research Laboratory (NBRL), School of Science, \\ RMIT University, GPO Box 2476, Melbourne, VIC 3000, Australia; s3437386@student.rmit.edu.au (P.D.L.); \\ pabudi.weerathunge@rmit.edu.au (P.W.); mandeep.singh@rmit.edu.au (M.S.) \\ * Correspondence: vipul.bansal@rmit.edu.au (V.B.); rajesh.ramanathan@rmit.edu.au (R.R.); \\ Tel.: +61-3-9925-2121 (V.B.); +61-3-9925-2887 (R.R.) \\ + Equal contributing authors.
}

check for

updates

Citation: Liyanage, P.D.;

Weerathunge, P.; Singh, M.; Bansal, V.;

Ramanathan, R. L-Cysteine as an

Irreversible Inhibitor of the

Peroxidase-Mimic Catalytic Activity

of 2-Dimensional Ni-Based

Nanozymes. Nanomaterials 2021, 11,

1285. https://doi.org/10.3390/

nano11051285

Academic Editor: Jose M. Palomo

Received: 2 March 2021

Accepted: 6 May 2021

Published: 13 May 2021

Publisher's Note: MDPI stays neutral with regard to jurisdictional claims in published maps and institutional affiliations.

Copyright: (c) 2021 by the authors. Licensee MDPI, Basel, Switzerland. This article is an open access article distributed under the terms and conditions of the Creative Commons Attribution (CC BY) license (https:// creativecommons.org/licenses/by/ $4.0 /)$.

\begin{abstract}
The ability to modulate the catalytic activity of inorganic nanozymes is of high interest. In particular, understanding the interactions of inhibitor molecules with nanozymes can bring them one step closer to the natural enzymes and has thus started to attract intense interest. To date, a few reversible inhibitors of the nanozyme activity have been reported. However, there are no reports of irreversible inhibitor molecules that can permanently inhibit the activity of nanozymes. In the current work, we show the ability of L-cysteine to act as an irreversible inhibitor to permanently block the nanozyme activity of 2-dimensional (2D) $\mathrm{NiO}$ nanosheets. Determination of the steady state kinetic parameters allowed us to obtain mechanistic insights into the catalytic inhibition process. Further, based on the irreversible catalytic inhibition capability of L-cysteine, we demonstrate a highly specific sensor for the detection of this biologically important molecule.
\end{abstract}

Keywords: nanozyme; L-cysteine; inhibitor; irreversible inhibitor; enzyme-mimic; peroxidase-mimic

\section{Introduction}

Nanozymes are inorganic nanomaterials that are believed to mimic the catalytic activity of natural enzymes [1-12]. To date, a range of metal, metal-oxide, metal sulfide and carbon-based nanozymes have been reported for their enzyme-mimicking catalytic activity. This activity has been employed for a range of applications ranging from controlling the bacterial growth, prodrug therapy, and photodynamic therapy to sensing of analytes [1-12]. A recent review reported that there are over 200 laboratories globally working on developing new nanozymes and expanding their applicability [13]. Of the different applications and fundamental investigations, one aspect that is gaining rapid attention is the ability to modulate the catalytic activity of nanozymes i.e., either enhance, deteriorate, temporarily inhibit or permanently inhibit its catalytic activity. To this end, metal ions [14-17], biomolecules such as ATP [18-20], cysteine [21-25], and glutathione [26,27] have all been successfully employed to modulate the catalytic activity of nanozymes. For instance, ATP was seen to enhance the catalytic activity of nanozymes while the amino acid cysteine was reported to inhibit their catalytic activity $[18,21]$. In this context, inhibition of the nanozyme activity can be considered akin to natural enzymes where an inhibitor molecule binds either to the active site of the enzyme or away from the active site of the enzyme resulting in complete loss of the catalytic activity or lowering the catalytic efficiency [28]. The process of inhibition can either be temporary or permanent. In the case of temporary inhibition, the inhibitor molecule binds reversibly to an enzyme (non-covalent interaction) such that it either temporarily inhibits or slows down the catalytic rate. In contrast, irreversible inhibitors bind covalently to the enzyme and permanently block its activity [29]. It is important to note that in the context of nanozymes, the only type of inhibition reported to date is reversible inhibition [30,31]. Further, in reversible inhibition, calculating the steady 
state kinetic parameters viz. Michaelis constant $\left(K_{m}\right)$ and maximum velocity of reaction $\left(V_{\max }\right)$ have offered deep insights into the mechanism of reversible inhibition (competitive vs. uncompetitive vs. non-competitive) [18]. Although such understanding has allowed the development of new inhibitor molecules for inorganic nanozymes, irreversible inhibitors of nanozymes have not been reported so far, at least to the best of the authors' knowledge.

Our group and others have previously established that L-cysteine can act as a nanozyme inhibitor, thereby inactivating the peroxidase-mimic catalytic activity resulting in a turn-off nanozyme sensor $[21,22,24,32]$. Most of these studies suggested that L-cysteine shields the surface of the nanozyme from the colorimetric substrate resulting in the loss of catalytic activity $[22,32]$. Our group was the first to show that in the case of $\mathrm{Gd}(\mathrm{OH})_{3}$ nanozyme, L-cysteine acts as a competitive inhibitor molecule for the nanozyme substrate which results in temporary inactivation of the catalytic activity [21]. While the investigation of the underlying mechanism has provided some understanding of the complex molecular interactions, it is still unclear if most nanozymes will reversibly interact with L-cysteine and if L-cysteine interacts reversibly, what is the mechanism of this reversible inhibition? Also, what parameters dictate the reversible interaction?

In the current study, we assess the mode of molecular interaction of L-cysteine with Ni-based nanozymes. For this, we developed a simple solution-based route to fabricate $\beta-\mathrm{Ni}(\mathrm{OH})_{2}$ and $\mathrm{NiO}$ nanomaterials. The catalytic enzyme-mimicking behaviour of both materials was established where the oxide phase showed superior peroxidase-mimic catalytic activity than the hydroxide phase. Exposure of the $\mathrm{NiO}$ nanoparticles to L-cysteine resulted in permanent inhibition of the catalytic activity where the degree of inhibition was dependent on the concentration of L-cysteine. Unlike natural enzymes where one inhibitor molecule typically results in the inactivation of a single enzyme molecule by interacting at the active site; in the case of nanozymes, the surface atoms of the nanoparticles play the equivalent role of the enzyme active sites [31]. The exposure of $\mathrm{NiO}$ to low concentrations of L-cysteine results only in partial loss of its activity as the surface of $\mathrm{NiO}$ is not blocked completely. In contrast, higher concentrations of L-cysteine result in complete loss of its catalytic activity. Unlike our previous work on $\mathrm{Gd}(\mathrm{OH})_{3}$ nanozyme, the nanozyme activity of $\mathrm{NiO}$ does not regain with time at a fixed L-cysteine concentration. Based on the enzyme kinetic theory, we observed that the affinity of the nanozyme to its substrate $\left(K_{m}\right)$ remained unchanged while the catalytic efficiency decreased. This suggests that more than one L-cysteine molecule is bound to the surface of each $\mathrm{NiO}$ blocking the surface atoms. Interestingly, other amino acids did not influence the activity of the $\mathrm{NiO}$ nanozyme showing high specificity of L-cysteine to bind to the $\mathrm{NiO}$ nanozyme. FTIR analysis further confirmed the presence of L-cysteine on the surface of the NiO nanozyme. Based on the high specificity of interactions between L-cysteine and NiO nanozyme, we further exploited this system to develop a simple L-cysteine sensor where the system allowed us to detect L-cysteine even in the presence of other amino acids and other sulfur containing compounds as contaminants either independently or in a mixture.

\section{Materials and Methods}

\subsection{Materials and Reagents}

Nickel(II) chloride, triethylamine, all peroxidase substrates and amino acids were purchased from Sigma Aldrich (Australia) and hydrogen peroxide was purchased from Chem Supply (Australia). All chemicals were used as received.

\subsection{Synthesis of $\beta-\mathrm{Ni}(\mathrm{OH})_{2}$ and $\mathrm{NiO}$}

A nickel precursor salt solution $\left(40 \mathrm{~mL}\right.$ of $1 \mathrm{M} \mathrm{NiCl}_{2}$ ) was first added to a round-bottom flask and heated to $80^{\circ} \mathrm{C}$ in an oil bath under continuous stirring where the temperature was continuously monitored using a thermometer. Once the desired temperature was achieved, triethylamine $(5 \mathrm{~mL})$ was introduced under continuous stirring. The reaction was allowed to stir for $1 \mathrm{~h}$ at a constant temperature of $80^{\circ} \mathrm{C}$. The resultant precipitate was allowed to cool and washed thoroughly using a mixture of acetone: methanol (1:1 $v / v)$ 
followed by vacuum drying. The greenish powder obtained contained the $\beta-\mathrm{Ni}(\mathrm{OH})_{2}$ nanomaterial. For the synthesis of the $\mathrm{NiO}$, the greenish powder of $\beta-\mathrm{Ni}(\mathrm{OH})_{2}$ was calcined at $400{ }^{\circ} \mathrm{C}$ for $12 \mathrm{~h}$ in the air to obtain a black powder of $\mathrm{NiO}$.

\subsection{Material Characterization}

Both nanomaterials were thoroughly characterized using a suite of materials characterization tools including transmission electron microscopy (TEM) and high resolution TEM (HR-TEM), energy dispersive X-ray (EDX) spectroscopy, X-Ray diffraction (XRD), atomic emission spectrometer (AES), Raman spectroscopy and Zetasizer. A detailed characterization is given in the Supplementary Information.

\subsection{Peroxidase-Mimic Catalytic Activity of Nanozymes and Optimization}

The catalytic performance of both nanozymes was first assessed by exposing a fixed concentration of the nanozyme (the equivalent of $1.5 \mathrm{mM} \mathrm{Ni}$ ion concentration) to $0.5 \mathrm{mM}$ 2,2'-azino-bis(3-ethylbenzothiazoline-6-sulfonic acid) diammonium salt (ABTS), 3, 3', 5, 5' tetramethylbenzidine (TMB) and o-phenylenediamine dihydrochloride (OPD) substrates in the presence and absence of $10 \mathrm{mM} \mathrm{H}_{2} \mathrm{O}_{2}$ in glycine- $\mathrm{HCl}$ buffer at $\mathrm{pH} 3$ and $30^{\circ} \mathrm{C}$. The change in the color of the substrates was monitored at $405 \mathrm{~nm}, 650 \mathrm{~nm}$ and $450 \mathrm{~nm}$, respectively, for all the three substrates, using a multimode plate reader. The change of absorbance $(\triangle \mathrm{A})$ was calculated by subtracting the absorbance value of the pristine nanozyme (background used as $\mathrm{A}_{0}$ ) from the absorbance at time point $t\left(A_{t}\right)$. The total volume of all reactions was maintained at $200 \mu \mathrm{L}$. To understand if the catalytic activity is an inherent property of the nanozyme, both nanozymes were independently exposed to acidic buffer ( $\mathrm{pH}$ 3) for $30 \mathrm{~min}$. The nanozymes were then centrifuged and the leached $\mathrm{Ni}$ ion concentration in the supernatant was determined by AES. Subsequently, the leached $\mathrm{Ni}$ ions from this experiment were also evaluated as a catalyst. Additionally, we also performed control experiments where known concentration of $\mathrm{Ni}^{2+}$ ions were used as the catalyst. The optimization of catalytic activity was assessed by changing the concentration of nanozyme (the equivalent of $\mathrm{Ni}$ ions from $0-1.75 \mathrm{mM}), \mathrm{pH}(1-8)$ and reaction temperature $\left(10-80^{\circ} \mathrm{C}\right)$ while keeping a fixed concentration of ABTS $(0.5 \mathrm{mM})$ and $\mathrm{H}_{2} \mathrm{O}_{2}(10 \mathrm{mM})$. The steady state kinetic parameters were calculated by performing experiments by varying either the ABTS $(0-8 \mathrm{mM})$ or $\mathrm{H}_{2} \mathrm{O}_{2}$ concentration $(0-200 \mathrm{mM})$ at a specific time point under optimum reaction conditions ( $\mathrm{pH} 3, \mathrm{Ni}$ concentration $1.5 \mathrm{mM}$ and temperature $30^{\circ} \mathrm{C}$ ). The absolute reaction velocity was calculated using Beer-Lambert Law wherein the absorbance value of oxidised ABTS was converted into product concentration using the molar extinction coefficient of oxidised ABTS $\left(36,000 \mathrm{M}^{-1} \cdot \mathrm{cm}^{-1}\right)$. The Michaelis constant $\left(K_{m}\right)$ and initial maximum velocity of the reaction $\left(V_{\max }\right)$ were calculated using non-linear curve fitting in OriginPro 2016 (OriginLab, Northampton, MA, USA).

\subsection{Interaction of L-Cysteine Amino Acid with NiO Nanozyme}

The $\mathrm{NiO}$ nanozyme was first exposed to three different concentrations of $\mathrm{L}$-cysteine $(10,100$ and $200 \mu \mathrm{M})$ for $10 \mathrm{~min}$. Following this, the substrates ABTS and $\mathrm{H}_{2} \mathrm{O}_{2}$ were added to the reaction and the inhibition of the catalytic performance was measured as a function of time. The ABTS $(0.5 \mathrm{mM}), \mathrm{H}_{2} \mathrm{O}_{2}(10 \mathrm{mM})$ and Ni concentration $(1.5 \mathrm{mM})$ were kept constant during these experiments. The nanozyme was also exposed to other commonly occurring amino acids and several thiolic compounds (cystine, cysteamine, thiourea, sodium 2-propanthiolate, and homocysteine) at a fixed concentration of $200 \mu \mathrm{M}$. The potential inhibition of the catalytic activity was calculated after $10 \mathrm{~min}$ of incubation with $\mathrm{ABTS}$ and $\mathrm{H}_{2} \mathrm{O}_{2}$ (the protocol was similar to the initial assay). A systematic concentration-dependent study was further performed where the NiO nanozyme was exposed to increasing concentrations of L-cysteine $(0-500 \mu \mathrm{M})$ keeping all other steps consistent. In another experiment, we exposed a fixed concentration of L-cysteine to $\mathrm{H}_{2} \mathrm{O}_{2}$ for $10 \mathrm{~min}$ followed by the addition of ABTS and $\mathrm{NiO}$ nanozyme. The linear regression of the change in absorbance was determined using OriginPro 2016. All sensor parameters 
were calculated using methods employed in our previous work [33]. The $K_{m}$ and $V_{\max }$ were also calculated in the presence of two different L-cysteine concentrations $(25 \mu \mathrm{M}$ and $50 \mu \mathrm{M})$.

\section{Results and Discussion}

A facile solution-based approach was used for the synthesis of $\beta-\mathrm{Ni}(\mathrm{OH})_{2}$ and $\mathrm{NiO}$ nanoparticles using triethylamine as the hydrolysing agent of the aqueous solution of $\mathrm{Ni}^{2+}$ ions. Figure 1 shows the morphological characteristics of both particles. TEM image of the $\beta-\mathrm{Ni}(\mathrm{OH})_{2}$ showed thin 2-dimensional (2D) sheet-like morphology (Figure 1a). Following the process of calcination to convert $\beta-\mathrm{Ni}(\mathrm{OH})_{2}$ to $\mathrm{NiO}$, the thin crumbled sheet-like morphology changed to irregular morphologies. However, the resulting $\mathrm{NiO}$ still retained the overall 2D sheet-like structures (Figure 1c). This morphological change may be attributed to the sintering effect during the calcination of the hydroxide phase to the corresponding oxide. The high crystallinity of both $\beta-\mathrm{Ni}(\mathrm{OH})_{2}$ (Figure $1 \mathrm{~b}$ ) and $\mathrm{NiO}$ (Figure 1d) is evident from lattice fringes observed under HR-TEM. The images show that in the case of $\beta-\mathrm{Ni}(\mathrm{OH})_{2}$, the interlayer spacing between the neighbouring fringes was ca. $0.27 \mathrm{~nm}$ which corresponds to the (010) crystal plane of the hexagonal $\beta-\mathrm{Ni}(\mathrm{OH})_{2}[34]$. For $\mathrm{NiO}$, the observed lattice spacing was ca. $0.21 \mathrm{~nm}$ corresponding to the (200) crystal plane of the cubic $\mathrm{NiO}$ [35]. Fast Fourier transformations (FFT) of the images reveal a well-defined diffraction pattern corresponding to the hexagonal and cubic phase of the $\beta-\mathrm{Ni}(\mathrm{OH})_{2}$ (inset in Figure $1 \mathrm{~b}$ ) and $\mathrm{NiO}$, respectively (inset in Figure 1d), attesting to the high crystallinity of these materials. The distribution of the different chemical species in these particles was further assessed, where the EDX spectra (Figure S1) obtained from both nanomaterials showed characteristic energy lines corresponding to $\mathrm{Ni}$ and $\mathrm{O}$, while the elemental maps (Figures S2 and S3) showed an even distribution of both elements across the nanomaterial surface.
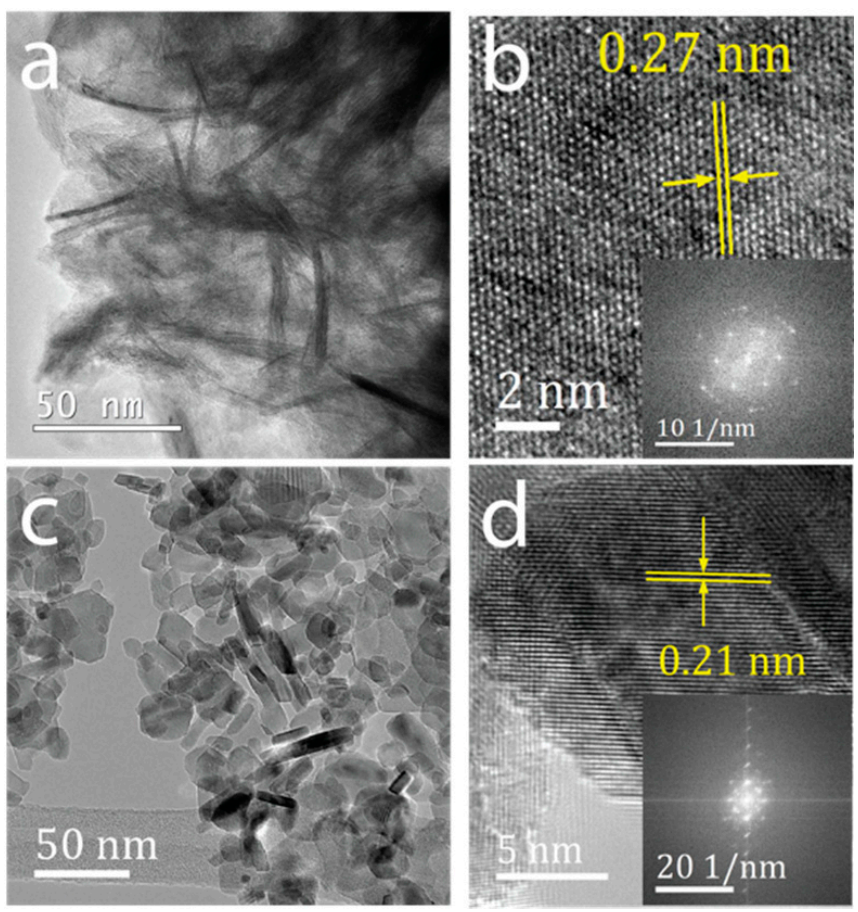

Figure 1. (a) Low and (b) high resolution TEM image of $\beta-\mathrm{Ni}(\mathrm{OH})_{2} ;(\mathbf{c})$ low and (d) high resolution TEM image of $\mathrm{NiO}$. The insets in $\mathrm{b}$ and $\mathrm{d}$ show the fast Fourier transformations obtained from the corresponding images.

XRD analysis (Figure 2a) confirmed that the greenish powder was indeed the hexagonal $\beta-\mathrm{Ni}(\mathrm{OH})_{2}$ phase (JCPDS: 74-2075) and the intense peak of the (100) suggests that the $\beta-\mathrm{Ni}(\mathrm{OH})_{2}$ nanosheets preferentially grow along the (100) plane, confirming their $2 \mathrm{D}$ mor- 
phology [35-38]. XRD pattern obtained from the black powder confirmed the face-centered cubic phase of $\mathrm{NiO}$ (JCPDS no 78-0423) with the most intense (200) plane supporting its 2D morphology, while the absence of any additional peak supporting a phase pure material. The Raman spectrum of $\beta-\mathrm{Ni}(\mathrm{OH})_{2}$ showed peaks at 312.6 and $448.3 \mathrm{~cm}^{-1}$ which are the characteristic lattice vibrational $E g$ and $A_{1 g}$ modes of the $\beta$-phase of nickel hydroxide (Figure $2 b$ ) $[39,40]$. Similarly, $\mathrm{NiO}$ showed three characteristic broad vibrational bands corresponding to the one-phonon (1P) mode at $497.4 \mathrm{~cm}^{-1}$ as well as the two-phonon (2P) modes at $726 \mathrm{~cm}^{-1}$ (transverse optical) and $1068 \mathrm{~cm}^{-1}$ (longitudinal optical). The broadening of the Raman bands in the case of $\mathrm{NiO}$ suggests the presence of structural defects or surface effects, both of which are well documented in the literature [40,41]. In such cases, the $1 \mathrm{P}$ band becomes pronounced with concomitant disappearance of the $906 \mathrm{~cm}^{-1}$ band [41].
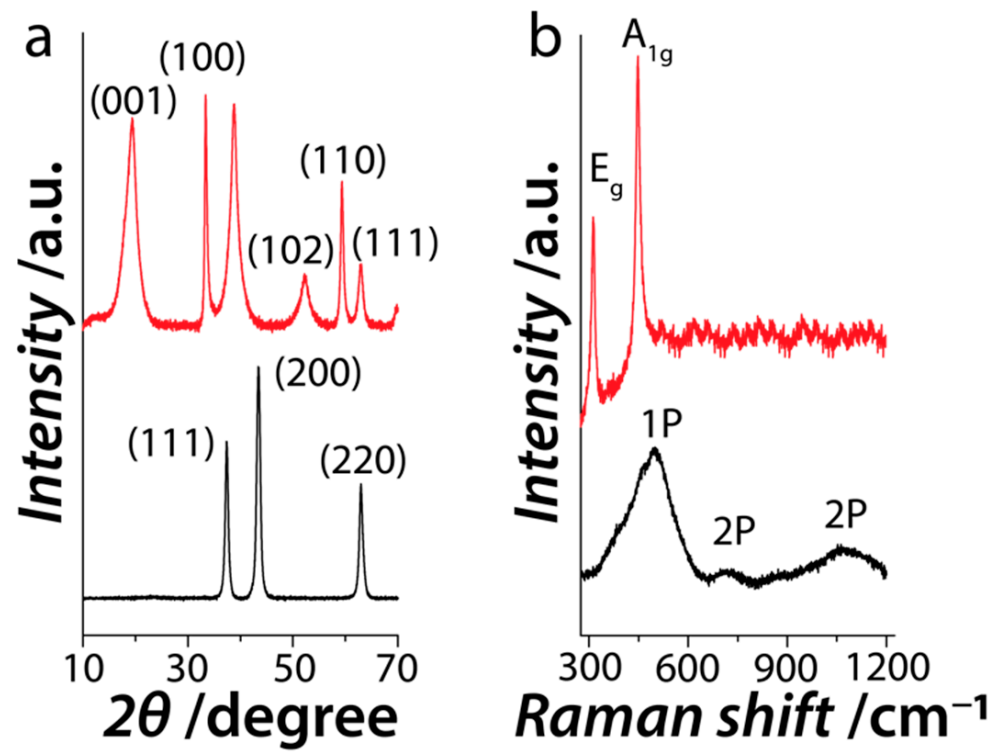

Figure 2. (a) XRD patterns and (b) Raman spectra obtained from the hexagonal $\beta-\mathrm{Ni}(\mathrm{OH})_{2}$ (red line) and cubic $\mathrm{NiO}$ (black line).

To establish the enzyme-mimic catalytic activity of the $\beta-\mathrm{Ni}(\mathrm{OH})_{2}$ and $\mathrm{NiO}$ nanomaterials, we first assessed their ability to oxidize chromogenic peroxidase substrates ABTS, TMB and OPD in the presence and absence of $\mathrm{H}_{2} \mathrm{O}_{2}$. In the case of oxidase-mimic activity, the nanomaterials would be able to catalyze the oxidation of these substrates in the absence of $\mathrm{H}_{2} \mathrm{O}_{2}$. However, the need for additional $\mathrm{H}_{2} \mathrm{O}_{2}$ to drive the oxidation of the chromogenic substrates would suggest that the nanomaterials mimic the natural peroxidase enzyme. Figure 3a shows that both nanomaterials could catalyze the oxidation of peroxidase substrate (ABTS) in the absence of $\mathrm{H}_{2} \mathrm{O}_{2}$, however, this oxidase-mimic activity is quite weak. A significant increase in the substrate oxidation (more than an order of magnitude increase) in the presence of $\mathrm{H}_{2} \mathrm{O}_{2}$ suggests that these materials predominantly mimic the peroxidase enzyme. It was also observed that both nanomaterials showed the highest catalytic activity towards ABTS oxidation, while they could oxidize TMB and OPD with lower efficiencies. This is interesting as nanozymes have been reported to have some degree of specificity towards substrates. This specificity is typically attributed to the surface charge on the nanozyme where positively charged nanomaterials are shown to have a high affinity towards negatively charged ABTS substrate while negatively charged nanomaterials show higher affinity for positively charged TMB and OPD substrates [42-45]. In the current study, zeta potential measurements revealed that both the $\beta-\mathrm{Ni}(\mathrm{OH})_{2}$ and $\mathrm{NiO}$ nanomaterials have a zeta potential value of $+11.4 \mathrm{mV}$ and $+21.4 \mathrm{mV}$, respectively at the physiological $\mathrm{pH}$. Given that the catalytic activity of these nanomaterials was assessed at $\mathrm{pH} 3$, the zeta potential values at this $\mathrm{pH}$ were $+27.6 \mathrm{mV}$ and $+41.1 \mathrm{mV}$, respectively. 
This observation corroborates well with our previous work, where we used triethylamine for the synthesis of $\mathrm{Gd}(\mathrm{OH})_{3}$ and $\mathrm{Gd}_{2} \mathrm{O}_{3}$ [21]. Based on the high positive charge on the surface, it is unsurprising that these materials show high catalytic activity for oxidizing ABTS substrate ( $\mathrm{pKa} \sim 1.5$ ). This supports the ongoing hypothesis that the substrate affinity in nanozymes most likely results from electrostatic interactions between the nanozyme and the substrate. Another observation is that both nanozymes also show the ability to oxidize positively charged TMB and OPD substrates, but with lower efficiency than ABTS. This is interesting as the high positive charge on the surface of the nanozyme and protonated form of TMB and OPD substrates in acidic medium should not lead to an electrostatic attraction ( $\mathrm{pK}_{\mathrm{a}}$ of TMB and OPD are $\sim 4.2$ and $\sim 4.4$, respectively). This suggests that the surface charge of the nanozyme is not the only factor that governs the ability of a nanozyme to oxidize different substrates. One such factor was recently pointed out where the catalytic activity of nanozymes was suggested to be dependent on their ability to cleave the leaving group in the substrates [29]. This suggests that there is a complex interplay between the substrate leaving group, the surface charge, and the inherent property of the nanomaterial in dictating the ability of a nanozyme to oxidize different substrates. Further, between the two materials, the $\mathrm{NiO}$ nanozyme showed higher catalytic activity than $\beta-\mathrm{Ni}(\mathrm{OH})_{2}$. Considering that both nanozymes showed high specificity in catalysing the oxidation of ABTS substrate, further studies were performed using ABTS as the substrate of choice.
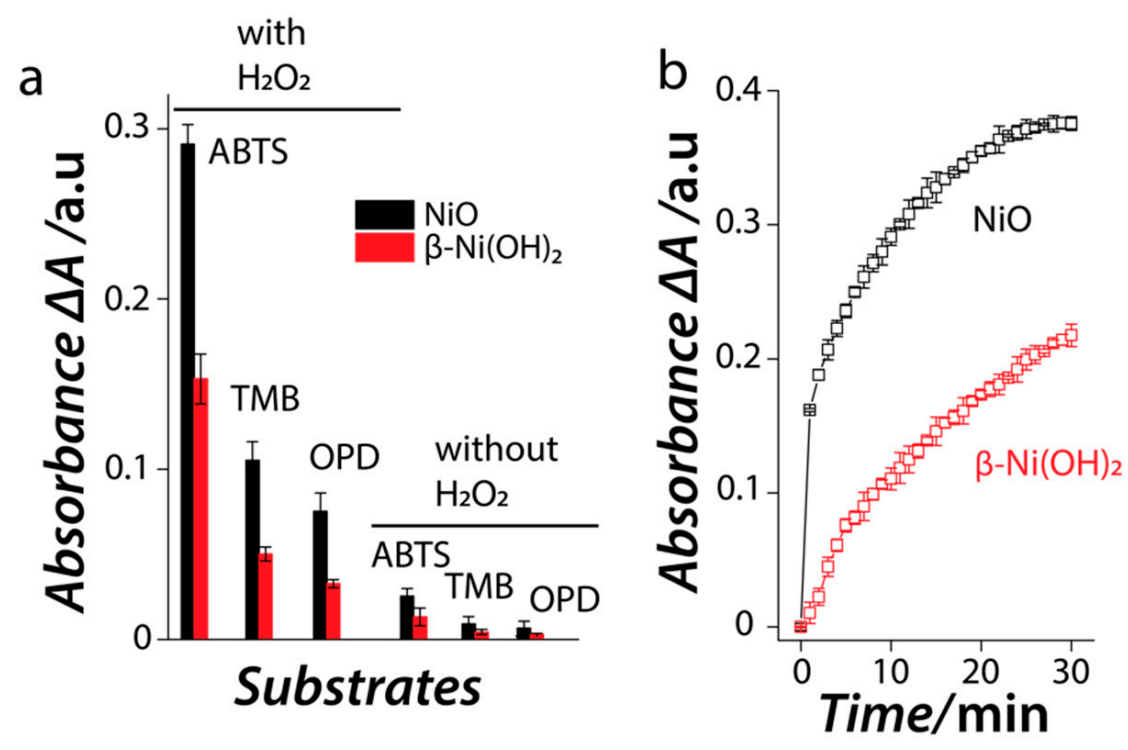

Figure 3. (a) The ability of the Ni-based nanozymes to promote the oxidation of different substrates $(0.5 \mathrm{mM})$ in the presence and absence of $\mathrm{H}_{2} \mathrm{O}_{2}(10 \mathrm{mM}) ;(\mathbf{b})$ the peroxidase-mimic catalytic activity of $\mathrm{NiO}$ and $\beta-\mathrm{Ni}(\mathrm{OH})_{2}$ nanozymes as a function of time at $\mathrm{pH} 3$ and $30^{\circ} \mathrm{C}$.

A time-dependent kinetic study of the catalytic reaction between the nanozymes and ABTS $/ \mathrm{H}_{2} \mathrm{O}_{2}$ substrates showed that in both cases the activity proceeds rapidly at initial time points (Figure $3 \mathrm{~b}$ ). In the case of $\mathrm{NiO}$ nanozyme, the activity saturates within $\sim 30 \mathrm{~min}$ of the reaction, while the $\beta-\mathrm{Ni}(\mathrm{OH})_{2}$ nanozyme showed a slow but steady increase in the catalytic activity as a function of time. To ensure that the catalytic activity was an inherent property of the two nanozymes and that there was no role of $\mathrm{Ni}$ ions potentially leached from the nanoparticles, control experiments were performed where the leached ion solution obtained after incubating the nanozymes under similar conditions $(10 \mathrm{mM}$ glycine $\mathrm{HCl}$ buffer ( $\mathrm{pH} \mathrm{3}$ ) at $30{ }^{\circ} \mathrm{C}$ for $30 \mathrm{~min}$ ) was used as a catalyst, which showed minimal catalytic activity (Figure S4a). Further, we also used five known concentrations of $\mathrm{Ni}^{2+}$ ions as a catalyst under similar conditions which showed no catalytic activity (Figure S4b). This suggests a direct contribution of the nanozymes in promoting the catalytic reaction. Additionally, the concentration of the leached $\mathrm{Ni}$ ions was also determined using AES. 
Minimal leaching was observed in all cases, which ascertained the high stability of these materials during catalysis (Figure S5).

Important reaction parameters such as the nanozyme concentration, $\mathrm{pH}$, and temperature were then optimized as these parameters have the potential to modulate the catalytic efficiency of a catalyst, a property akin to natural enzymes and other nanozymes [46,47]. The catalytic activity of both nanozymes increased with the increasing nanozyme concentration (Figure S6a). The $\mathrm{NiO}$ nanozyme showed maximum catalytic activity at $1.5 \mathrm{mM} \mathrm{Ni}$ equivalent concentration where further increase in the Ni concentration had minimal effect on the catalytic efficiency. In contrast, the catalytic activity of the $\beta-\mathrm{Ni}(\mathrm{OH})_{2}$ nanozyme continued to increase up to the highest tested concentration $(1.75 \mathrm{mM} \mathrm{Ni})$. Both nanozymes showed optimal activity at $30^{\circ} \mathrm{C}$ (Figure S6b) and pH 3 (Figure S6c). Further increase in the temperature or moving from acidic conditions towards neutral or alkaline $\mathrm{pH}$ resulted in the loss of catalytic activity.

Further studies were performed using the optimal conditions for both nanozymes-Ni concentration of $1.5 \mathrm{mM}, \mathrm{pH} 3$ and temperature of $30^{\circ} \mathrm{C}$. Using the enzyme kinetic theory, we also calculated the Michaelis constant $\left(K_{m}\right)$ and maximum initial velocity $\left(V_{\max }\right)$ for both nanozymes. For this, the catalytic reaction was monitored by varying one substrate concentration at a time while keeping the concentration of the second substrate fixed. A plot of the initial velocity $\left(V_{0}\right)$ vs. the substrate concentration showed typical Michaelis-Menten curves (Figure S7). These values were then used for the Lineweaver-Burk plot to determine the $K_{m}$ and $V_{\max }$ (Table 1). The calculated $K_{m}$ values suggest that the $\mathrm{NiO}$ nanozyme has a higher affinity for $\mathrm{H}_{2} \mathrm{O}_{2}$ substrate than ABTS, while the $\beta-\mathrm{Ni}(\mathrm{OH})_{2}$ nanozyme has a higher affinity for ABTS substrate. This is an interesting observation, as most of the inorganic nanozymes show a high affinity for the chromogenic substrate, while the lower affinity to $\mathrm{H}_{2} \mathrm{O}_{2}$ [21,24,48-50]. In the current study, $\mathrm{NiO}$ shows a higher affinity for $\mathrm{H}_{2} \mathrm{O}_{2}$ suggesting that it is the affinity of the nanozyme towards the chromogenic substrate that limits the catalytic reaction. The comparison of the $V_{\max }$ values of two nanozymes towards ABTS oxidation suggests that the $\mathrm{NiO}$ nanozyme is a better catalyst than $\beta-\mathrm{Ni}(\mathrm{OH})_{2}$ nanozyme. Considering that $\mathrm{NiO}$ nanozyme is a superior peroxidase-mimic, further interaction studies were performed using $\mathrm{NiO}$ as a model nanozyme to understand its interaction with $\mathrm{L}$ cysteine amino acid.

Table 1. Apparent enzyme kinetic parameters calculated for the $\mathrm{NiO}$ and $\beta-\mathrm{Ni}(\mathrm{OH})_{2}$ nanozymes at $\mathrm{pH} 3,30^{\circ} \mathrm{C}$ and $\mathrm{Ni}$ ion concentration of $1.5 \mathrm{mM}$.

\begin{tabular}{ccccc}
\hline & \multicolumn{3}{c}{$\mathbf{N i O}$} & \multicolumn{2}{c}{$\beta$-Ni(OH) } \\
\cline { 2 - 5 } & ABTS & $\mathbf{H}_{\mathbf{2}} \mathbf{O}_{\mathbf{2}}$ & ABTS & $\mathbf{H}_{\mathbf{2}} \mathbf{O}_{\mathbf{2}}$ \\
\hline$K_{m}(\mathrm{mM})$ & 17.5 & 14.8 & 7 & 14 \\
$V_{\max }(\mathrm{mM} / \mathrm{s})$ & $5.3 \times 10^{-4}$ & $1.1 \times 10^{-4}$ & $2.3 \times 10^{-4}$ & $8.7 \times 10^{-4}$ \\
\hline
\end{tabular}

Our previous work with Gd-based nanozymes showed that L-cysteine amino acid acts as a reversible inhibitor [51,52]. In that case, L-cysteine did not act as a catalyst poison but instead, it interacted with the nanozyme through a competitive inhibition process where there was a competition between L-cysteine and the peroxidase substrates to bind to the surface of the nanozyme. The first line of thought in the current case of Ni-based nanozymes was-would a similar reversible interaction occur when $\mathrm{NiO}$ nanozyme is exposed to $\mathrm{L}$ cysteine? For this, three independent concentrations of L-cysteine were exposed to a fixed concentration of $\mathrm{NiO}$ nanozyme in the presence of $\mathrm{ABTS} / \mathrm{H}_{2} \mathrm{O}_{2}$ and the reaction was monitored as a function of time. To our surprise, at all the tested L-cysteine concentrations, the nanozyme could initially catalyze the oxidation of ABTS substrate with an almost equivalent pace irrespective of the concentration of L-cysteine (Figure 4). However, after this initial burst phase, the reaction saturates with increasing rapidity with an increase in L-cysteine concentration. This observation is in stark contrast to our previous study on Gd-based nanozymes where the activity was completely blocked initially in the presence 
of L-cysteine and subsequently regained with time even at extremely high L-cysteine concentrations (Figure S8) [21]. Interestingly, in the current case, the catalytic activity of the $\mathrm{NiO}$ nanozyme does not improve with time in cases where L-cysteine concentration is high enough to block the initial activity $(100$ and $200 \mu \mathrm{M})$. This suggests that L-cysteine may act as an irreversible inhibitor of the catalytic activity of the NiO nanozyme.

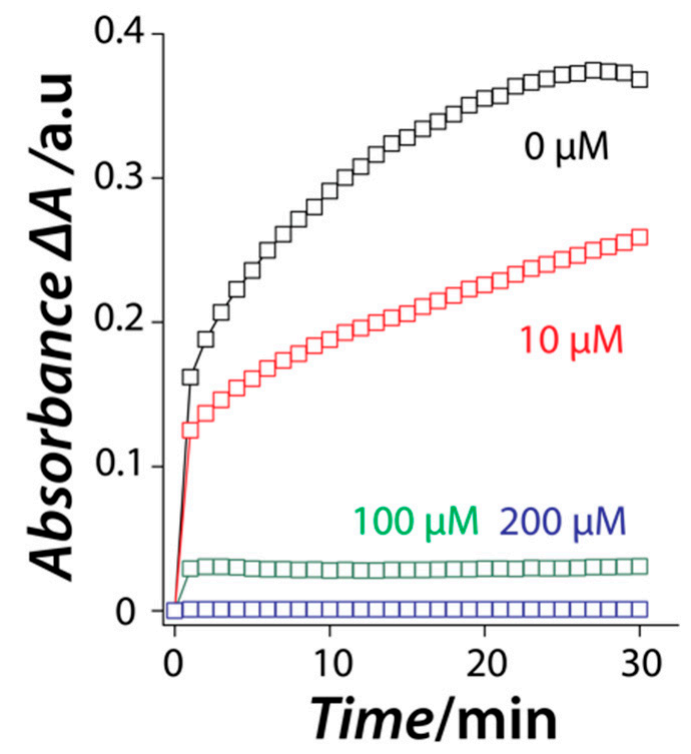

Figure 4. The inhibition of the peroxidase-mimic catalytic activity of the $\mathrm{NiO}$ nanozyme as a function of time in the absence and presence of different L-cysteine concentrations (Reaction conditions: ABTS-0.5 mM; $\mathrm{H}_{2} \mathrm{O}_{2}-10 \mathrm{mM} ; \mathrm{pH}-3.0$, temperature- $30{ }^{\circ} \mathrm{C}$ ).

This would mean that a stable nanozyme-cysteine complex is formed as soon as the $\mathrm{NiO}$ nanozyme is exposed to L-cysteine. The formation of this stable complex will significantly deplete the population of free L-cysteine (inhibitor) in the reaction. Based on enzyme kinetic theory, such inhibitors bind to the natural enzyme with an apparent affinity close to the concentration of the active sites of the enzyme, i.e., one inhibitor molecule inactivating a single enzyme molecule. This implies that as the concentration of the inhibitor is increased, at a particular inhibitor concentration, one would observe a complete loss of the enzyme activity. In nanozymes, the surface atoms are considered to play the role of the active site, which is likely to result in multiple active sites within a single nanozyme particle. This means that a nanozyme-driven reaction would require very high concentrations of the inhibitor molecule to completely inactivate a single nanozyme. If we consider the potential impact of this scenario on the steady-state kinetics $\left(K_{m}\right.$ and $\left.V_{\max }\right)$ of the nanozyme, we should expect to see no change in the $K_{m}$, as the irreversible binding of L-cysteine to the nanozyme in the initial phase should not influence the simultaneous binding of substrate molecules to the surface of the nanozyme. However, given that fewer free surface atoms are consequently available to interact with the substrate, we should see a decrease in the $V_{\max }$ for nanozyme-mediated substrate oxidation. To validate this hypothesis, we calculated the $K_{m}$ and $V_{\max }$ in the presence and absence of L-cysteine (Figure S9). In line with our hypothesis, we do indeed observe a decrease in the $V_{\max }$ for the substrates ABTS and $\mathrm{H}_{2} \mathrm{O}_{2}$ as we increase the concentration of L-cysteine, while the $K_{m}$ remains constant (Figure S9 and Table S1).

To further validate the irreversible inhibition of $\mathrm{NiO}$ nanozyme by L-cysteine, we employed FTIR spectroscopy (Figure S10). The above hypothesis relies on the premise that L-cysteine permanently binds to the surface of the nanozyme, which should become evident from FTIR studies. The FTIR of the $\mathrm{NiO}$ showed a broad peak at ca. $3540 \mathrm{~cm}^{-1}$ associated with the asymmetric and symmetric stretching vibrations of the $-\mathrm{OH}$ group (absorbed water molecules and the surface hydroxyls) [53-55]. The FTIR spectrum of 
pristine L-cysteine amino acid showed characteristic peaks of the $-\mathrm{COO}$ stretch $\left(1581 \mathrm{~cm}^{-1}\right.$, $\left.1422 \mathrm{~cm}^{-1}\right)$, -SH bend and stretching $\left(2550 \mathrm{~cm}^{-1}\right.$ and $\left.943 \mathrm{~cm}^{-1}\right)$ as well as those from the amine functional group $\left(3184 \mathrm{~cm}^{-1}\right)[56,57]$. Following the interaction of the L-cysteine and $\mathrm{NiO}$ nanozyme, the particles were extracted and washed. The FTIR spectrum of the washed nanozyme showed additional strong peaks arising from the -SH bend and -COO stretch, which were absent in the case of pristine $\mathrm{NiO}$ nanozyme [56,57]. These observations affirm the strong binding ability of L-cysteine to the $\mathrm{NiO}$ nanozyme, supporting the formation of a stable nanozyme-inhibitor complex.

Classical enzyme kinetic models suggest that irreversible inhibitors or tight binding inhibitors can display a non-competitive phenotype [57]. In the current case, based on steady state kinetics, the inhibitory activity of L-cysteine shows features corresponding to non-competitive inhibition, while the time-dependent activity shows that the catalytic activity of the nanozyme does not recover with time. Both of these aspects together confirms that L-cysteine in fact acts as an irreversible inhibitor of the $\mathrm{NiO}$ nanozyme activity. To further understand if the interaction of L-cysteine with $\mathrm{NiO}$ leads to irreversible changes in the nanozyme, we also performed XRD studies following the exposure to L-cysteine of $\mathrm{NiO}$. As evident from the XRD spectra before and after L-cysteine exposure (Figure S11), we observe no change in the chemical nature of the $\mathrm{NiO}$ nanozyme.

Having established that L-cysteine binds irreversibly to the NiO nanozyme, it was pertinent to understand if L-cysteine is the only amino acid that has this capability. To understand this aspect, we exposed the $\mathrm{NiO}$ nanozyme to a fixed concentration of other commonly occurring amino acids including L-methionine which is another sulfur-containing amino acid. In all cases, we observed minimal interaction of the amino acid with the nanozyme resulting in no or minimal loss of the catalytic activity (Figure 5a). In contrast, if the same amino acids were mixed with a fixed concentration of L-cysteine, we observed an immediate loss of the catalytic activity. Further studies were performed by exposing the $\mathrm{NiO}$ nanozyme to several thiolic compounds (cystine, cystamine, thiourea, sodium 2-propanthiolate, and homocysteine). We observed that these sulfur containing molecules resulted in some loss of the nanozyme activity (Figure $5 b$ ). However, the influence of these thiolic compounds on the activity of $\mathrm{NiO}$ nanozyme is remarkably smaller in contrast to the near-complete loss of activity induced by L-cysteine.

Importantly, in the above experiments, the $\mathrm{NiO}$ nanozyme was first exposed to $\mathrm{L}$ cysteine or other interfering molecules prior to the addition of the chromogenic substrate ABTS and the co-substrate $\mathrm{H}_{2} \mathrm{O}_{2}$. It is, however, known that $\mathrm{H}_{2} \mathrm{O}_{2}$ can oxidize L-cysteine to form cysteine [58]. This catalytic activity is significantly faster at neutral or alkaline $\mathrm{pH}$. In the current case, if this were to occur, then we should not have observed any inhibition of the nanozyme activity, especially considering that cystine itself didn't significantly block the nanozyme activity. To validate the influence of $\mathrm{H}_{2} \mathrm{O}_{2}$ on L-cysteine in the presence of the nanozyme, we performed additional experiments in which, we first exposed L-cysteine to $\mathrm{H}_{2} \mathrm{O}_{2}$ for 10 min and then added the $\mathrm{NiO}$ nanozyme and ABTS. The plot of ABTS oxidation as a function of time shows that the oxidation of ABTS is only marginally inhibited in this case (Figure S12). This suggests that the formation of a stable cysteine-nanozyme complex protects L-cysteine against $\mathrm{H}_{2} \mathrm{O}_{2}$-induced oxidation. This experiment also validates that it is irreversible inhibition of the nanozyme activity by L-cysteine, and not a potential parallel reaction pathway involving $\mathrm{H}_{2} \mathrm{O}_{2}$ consumption during L-cysteine oxidation that results in the reduction of the nanozyme activity.

We, then employed this high specificity of the $\mathrm{NiO}$ nanozyme to interact with Lcysteine for the quantitative detection of L-cysteine. Different concentrations of L-cysteine were exposed to a fixed concentration of the $\mathrm{NiO}$ nanozyme along with both ABTS and $\mathrm{H}_{2} \mathrm{O}_{2}$ substrates. The change in absorbance due to the peroxidase-mimic catalytic activity (with respect to activity without L-cysteine) was plotted against the L-cysteine concentration (Figure 6). 
a

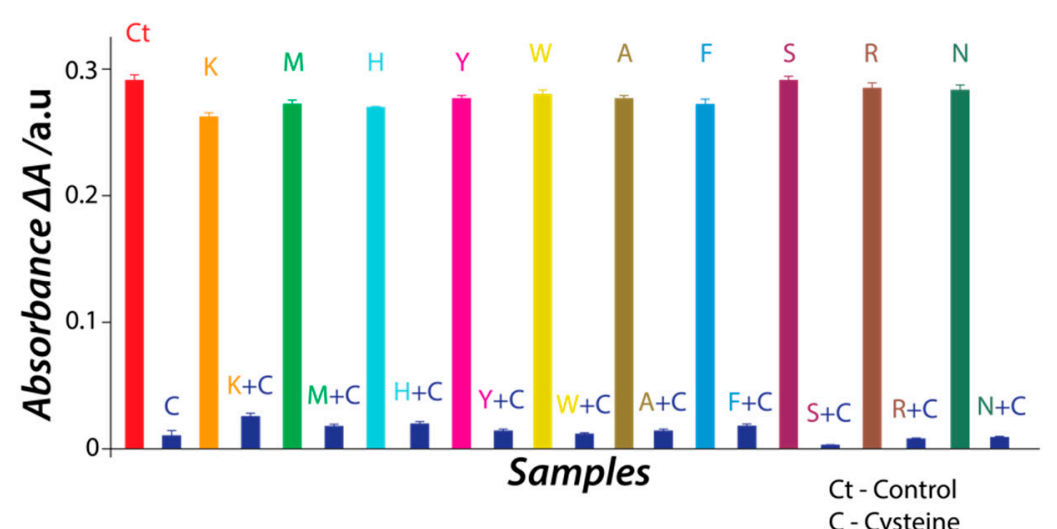

b

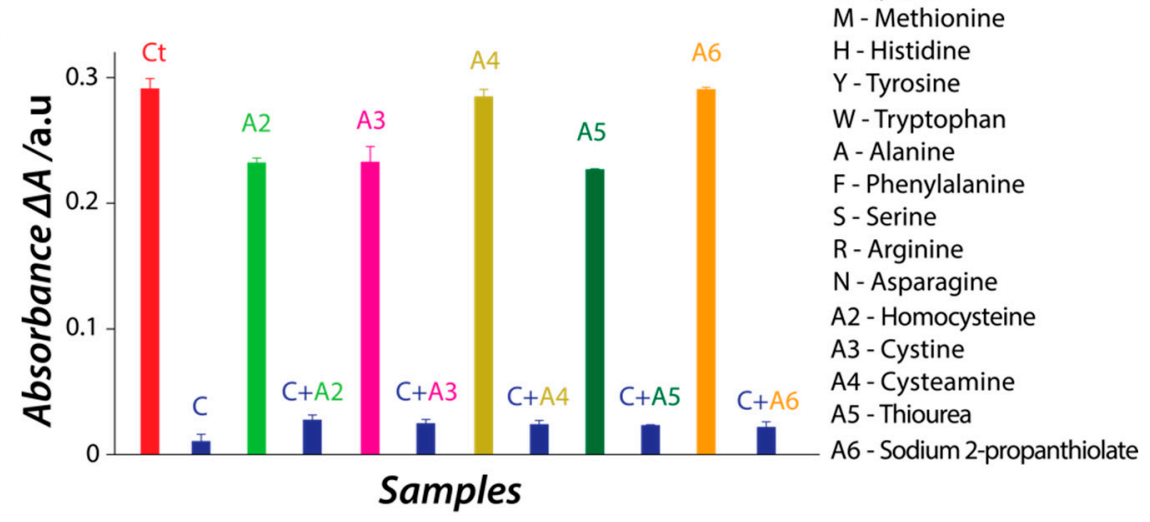

Figure 5. (a) The inhibition of the peroxidase-mimic catalytic activity of NiO nanozyme in the presence of different amino acids either independently or in combination with L-cysteine (200 $\mu \mathrm{M}$ concentration of amino acids and L-cysteine); (b) the inhibition of peroxidase-mimic catalytic activity of $\mathrm{NiO}$ nanozyme in the presence of different sulfur containing compounds $(200 \mu \mathrm{M})$ either independently or in combination with L-cysteine.

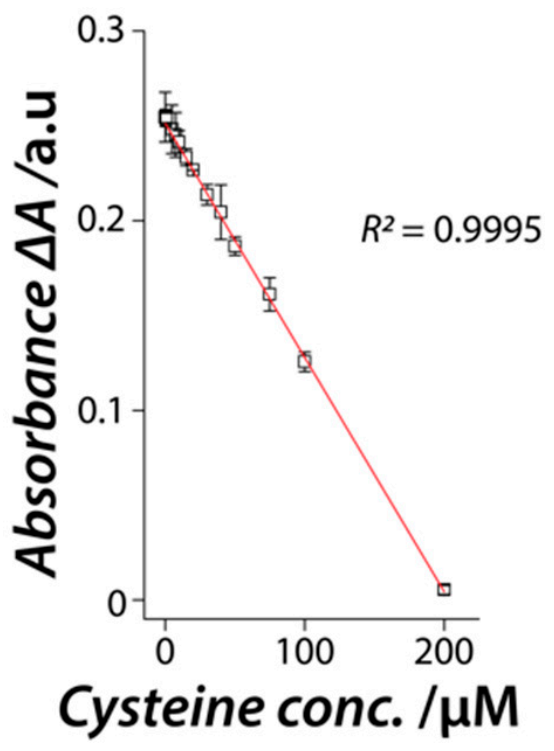

Figure 6. A plot of the change in absorbance due to the oxidation of ABTS substrate as a result of the catalytic activity of $\mathrm{NiO}$ nanozyme vs. L-cysteine concentration showing a linear regression correlation.

A linear correlation was observed between $0.1 \mu \mathrm{M}-200 \mu \mathrm{M}$ L-cysteine concentration, beyond which, the activity saturated. Ten independent experiments with three different concentrations (lowest, mid and highest) of L-cysteine in the dynamic linear range were 
used to determine the accuracy and precision of L-cysteine detection. The results showed over $96.5 \%$ precision for all concentrations $(0.1 \mu \mathrm{M}-96.96 \%, 50 \mu \mathrm{M}-96.67 \%$, and $200 \mu \mathrm{M}-$ $98.45 \%$ ) and $100 \%$ accuracy at a significance of $10 \%$ confidence level. This outlines the robustness of the $\mathrm{NiO}$ nanozyme system as a potential L-cysteine sensor.

\section{Conclusions}

The current study establishes the peroxidase-mimic catalytic activity of two Ni-based $2 \mathrm{D}$ nanomaterials viz. $\mathrm{NiO}$ and $\beta-\mathrm{Ni}(\mathrm{OH})_{2}$. Both nanozymes showed high specificity towards oxidation of negatively charged ABTS substrate over other positively charged substrates. The activity of the oxide phase was found superior to the hydroxide phase. Importantly, our study for the first-time establishes L-cysteine as an irreversible inhibitor to permanently block the catalytic activity of the $\mathrm{NiO}$ nanozyme. Given that surface atoms play the role of active sites in nanozymes, the inhibition of activity was found to be dependent on the concentration of L-cysteine. In depth analysis using enzyme kinetic theory confirmed that the addition of L-cysteine to the reaction did not affect the affinity of the nanozyme to its substrates but only reduced the catalytic efficiency. This ability to block the enzyme-mimic activity was specific to L-cysteine amino acid. The specific nature of this interaction allowed the fabrication of a simple colorimetric sensor for L-cysteine using the $\mathrm{NiO}$ nanozyme system. This sensor allowed us to detect L-cysteine in the presence of other amino acids as contaminants either independently or in a mixture. This work opens a new avenue of research to find molecules that bind either reversibly or irreversibly to nanozymes bringing them one-step closer to natural enzymes.

Supplementary Materials: The following are available online at https:/ / www.mdpi.com/article/10 $.3390 /$ nano11051285/s1, Figure S1. The EDX spectrum obtained from (a) $\beta-\mathrm{Ni}(\mathrm{OH})_{2}$ and (b) $\mathrm{NiO}$, Figure S2. EDS elemental maps obtained from a single $\beta-\mathrm{Ni}(\mathrm{OH})_{2}$ particle, Figure S3. EDS elemental maps obtained from a cluster of $\mathrm{NiO}$ particles, Figure S4. (a) A plot of the absorbance vs. the reaction time of the two nanozymes and leached ions; $(\mathbf{b})$ a plot of the absorbance vs. the reaction time of the two nanozymes and known concentrations of $\mathrm{Ni}^{2+}$ ions as a catalyst, Figure S5. The concentration of $\mathrm{Ni}$ ion in solution after the incubation of the $\mathrm{Ni}(\mathrm{OH})_{2}$ (red bars) and $\mathrm{NiO}$ nanozyme (black bars) in $\mathrm{pH} 3$ buffer for $30 \mathrm{~min}$, followed by centrifugation to obtain nanozyme as the pellet and potentially leached $\mathrm{Ni}^{2+}$ ions in the supernatant, Figure S6. The effect of the (a) nanozyme concentration, (b) temperature, and (c) $\mathrm{pH}$ on the peroxidase-mimic catalytic activity of the $\mathrm{Ni}(\mathrm{OH})_{2}$ (red bars) and $\mathrm{NiO}$ (black bars) nanozyme. The error bars represent the standard deviation obtained from three independent experiments, Figure S7. $(\mathbf{a}, \mathbf{b})$ Michaelis-Menten and $(\mathbf{c}, \mathbf{d})$ Lineweaver-Burk plots for the $\beta-\mathrm{Ni}(\mathrm{OH})_{2}$ nanozyme (red) and $\mathrm{NiO}$ nanozyme (black). The error bars represent the standard deviations obtained from three independent experiments. The non-linear fitting for Michaelis-Menten and linear fitting for Lineweaver-Burk was performed using OriginPro 2016. (Reaction conditions include $\mathrm{pH} 3,30^{\circ} \mathrm{C}$ and $\mathrm{Ni}$ concentration of $1.5 \mathrm{mM}$; when ABTS concentration was changed, $\mathrm{H}_{2} \mathrm{O}_{2}$ concentration was maintained at $10 \mathrm{mM}$; when $\mathrm{H}_{2} \mathrm{O}_{2}$ concentration was changed, ABTS concentration was maintained at $0.5 \mathrm{mM}$ ), Figure S8. Change in the nanozyme activity of $\mathrm{Gd}(\mathrm{OH})_{3}$ nanorods with increasing concentration of L-Cys as a function of time, Figure S9. Lineweaver-Burk (LB) plots obtained for the $\mathrm{NiO}$ nanozyme in the presence of different concentrations of L-cysteine inhibitor. (a) shows the LB plots with varying ABTS concentration at a fixed $10 \mathrm{mM} \mathrm{H}_{2} \mathrm{O}_{2}$ concentration while (b) shows the $\mathrm{LB}$ plots with varying $\mathrm{H}_{2} \mathrm{O}_{2}$ concentration at a fixed $0.5 \mathrm{mM}$ ABTS concentration. The error bars represent the standard deviations obtained from three independent experiments. The linear fitting was performed using OriginPro 2016, Figure S10. FTIR spectral analysis for NiO nanozyme (black), L-cysteine (red) and $\mathrm{NiO}$ and L-cysteine interaction (blue), Figure S11. XRD spectra obtained from $\mathrm{NiO}$ nanozyme before and after its exposure to L-cysteine, Figure S12. A plot of the change in absorbance as a function of time for (i) pristine $\mathrm{NiO}$ nanozyme exposed to ABTS and $\mathrm{H}_{2} \mathrm{O}_{2}$; (ii) L-cysteine exposed to $\mathrm{H}_{2} \mathrm{O}_{2}$ for $10 \mathrm{~min}$ followed by the addition of ABTS and $\mathrm{NiO}$ and $\mathrm{NiO}$ exposed to L-cysteine for $10 \mathrm{~min}$ followed by the addition of ABTS and $\mathrm{H}_{2} \mathrm{O}_{2}$, Table S1. Comparison of apparent enzyme kinetic parameters for the $\mathrm{NiO}$ nanozyme in absence and presence of different concentrations of L-cysteine. 
Author Contributions: Conceptualization, V.B. and R.R.; methodology, P.D.L., P.W. and M.S.; validation, P.D.L., P.W. and M.S.; formal analysis, P.D.L., P.W., M.S., V.B., and R.R.; investigation, P.D.L., P.W. and M.S.; resources, V.B. and R.R.; data curation, P.D.L., P.W. and M.S.; writing-original draft preparation, P.D.L. and P.W.; supervision, V.B. and R.R.; project administration, V.B. and R.R.; funding acquisition, V.B. and R.R. All authors have read and agreed to the published version of the manuscript.

Funding: V.B. and R.R. acknowledge the Australian Research Council (ARC) for funding this project through an ARC Discovery (DP170103477) Grant.

Data Availability Statement: No new data were created or analyzed in this study. Data sharing is not applicable to this article.

Acknowledgments: The authors recognise the generous support of the Ian Potter Foundation towards establishing the Sir Ian Potter NanoBioSensing Facility at RMIT University. The authors acknowledge the support from the RMIT Microscopy and Microanalysis Facility (RMMF) for technical assistance and providing access to characterization facilities.

Conflicts of Interest: The authors declare no conflict of interest.

\section{References}

1. Breslow, R. Artificial enzymes. Science 1982, 218, 532-537. [CrossRef]

2. Breslow, R. Biomimetic chemistry and artificial enzymes: Catalysis by design. Acc. Chem. Res. 1995, 28, 146-153. [CrossRef]

3. Kuah, E.; Toh, S.; Yee, J.; Ma, Q.; Gao, Z. Enzyme Mimics: Advances and Applications. Chemistry 2016, 22, 8404-8430. [CrossRef]

4. Karim, M.N.; Singh, M.; Weerathunge, P.; Bian, P.; Zheng, R.; Dekiwadia, C.; Ahmed, T.; Walia, S.; Della Gaspera, E.; Singh, S. Visible-light-triggered reactive-oxygen-species-mediated antibacterial activity of peroxidase-mimic CuO nanorods. ACS Appl. Nano Mater. 2018, 1, 1694-1704. [CrossRef]

5. Weerathunge, P.; Behera, B.K.; Zihara, S.; Singh, M.; Prasad, S.N.; Hashmi, S.; Mariathomas, P.R.D.; Bansal, V.; Ramanathan, R. Dynamic interactions between peroxidase-mimic silver NanoZymes and chlorpyrifos-specific aptamers enable highly-specific pesticide sensing in river water. Anal. Chim. Acta. 2019, 1083, 157-165. [CrossRef]

6. Weerathunge, P.; Ramanathan, R.; Shukla, R.; Sharma, T.K.; Bansal, V. Aptamer-controlled reversible inhibition of gold nanozyme activity for pesticide sensing. Anal. Chem. 2014, 86, 11937-11941. [CrossRef]

7. Weerathunge, P.; Ramanathan, R.; Torok, V.A.; Hodgson, K.; Xu, Y.; Goodacre, R.; Behera, B.K.; Bansal, V. Ultrasensitive colorimetric detection of murine norovirus using NanoZyme aptasensor. Anal. Chem. 2019, 91, 3270-3276. [CrossRef]

8. Karim, M.N.; Anderson, S.R.; Singh, S.; Ramanathan, R.; Bansal, V. Nanostructured silver fabric as a free-standing NanoZyme for colorimetric detection of glucose in urine. Biosens. Bioelectron. 2018, 110, 8-15. [CrossRef] [PubMed]

9. Sharma, T.K.; Ramanathan, R.; Weerathunge, P.; Mohammadtaheri, M.; Daima, H.K.; Shukla, R.; Bansal, V. Aptamer-mediated 'turn-off/turn-on'nanozyme activity of gold nanoparticles for kanamycin detection. Chem. Commun. 2014, 50, 15856-15859. [CrossRef] [PubMed]

10. Weerathunge, P.; Pooja, D.; Singh, M.; Kulhari, H.; Mayes, E.L.; Bansal, V.; Ramanathan, R. Transferrin-conjugated quasi-cubic SPIONs for cellular receptor profiling and detection of brain cancer. Sens. Actuat. B 2019, 297, 126737. [CrossRef]

11. Naveen Prasad, S.; Weerathunge, P.; Karim, M.N.; Anderson, S.; Hashmi, S.; Mariathomas, P.D.; Bansal, V.; Ramanathan, R. Non-invasive detection of glucose in human urine using a color-generating copper NanoZyme. Anal. Bioanal. Chem. 2021, 413, 1279-1291. [CrossRef]

12. Das, R.; Dhiman, A.; Kapil, A.; Bansal, V.; Sharma, T.K. Aptamer-mediated colorimetric and electrochemical detection of Pseudomonas aeruginosa utilizing peroxidase-mimic activity of gold NanoZyme. Anal. Bioanal. Chem. 2019, 411, 1229-1238. [CrossRef]

13. Wu, J.; Wang, X.; Wang, Q.; Lou, Z.; Li, S.; Zhu, Y.; Qin, L.; Wei, H. Nanomaterials with enzyme-like characteristics (nanozymes): Next-generation artificial enzymes (II). Chem. Soc. Rev. 2019, 48, 1004-1076. [CrossRef] [PubMed]

14. Lien, C.W.; Chen, Y.C.; Chang, H.T.; Huang, C.C. Logical regulation of the enzyme-like activity of gold nanoparticles by using heavy metal ions. Nanoscale 2013, 5, 8227-8234. [CrossRef]

15. Tseng, C.-W.; Chang, H.-Y.; Chang, J.-Y.; Huang, C.-C. Detection of mercury ions based on mercury-induced switching of enzyme-like activity of platinum/gold nanoparticles. Nanoscale 2012, 4, 6823-6830. [CrossRef] [PubMed]

16. Wu, Y.-H.; Chu, L.; Liu, W.; Jiang, L.; Chen, X.-Y.; Wang, Y.-H.; Zhao, Y.-L. The screening of metal ion inhibitors for glucose oxidase based on the peroxidase-like activity of nano-Fe3O4. RSC Adv. 2017, 7, 47309-47315. [CrossRef]

17. Huang, L.; Zhu, Q.; Zhu, J.; Luo, L.; Pu, S.; Zhang, W.; Zhu, W.; Sun, J.; Wang, J. Portable Colorimetric Detection of Mercury(II) Based on a Non-Noble Metal Nanozyme with Tunable Activity. Inorg. Chem. 2019, 58, 1638-1646. [CrossRef]

18. Shah, J.; Singh, S. Unveiling the role of ATP in amplification of intrinsic peroxidase-like activity of gold nanoparticles. 3 Biotech 2018, 8, 67. [CrossRef] [PubMed]

19. Lin, Y.; Huang, Y.; Ren, J.; Qu, X. Incorporating ATP into biomimetic catalysts for realizing exceptional enzymatic performance over a broad temperature range. NPG Asia Mater. 2014, 6, e114. [CrossRef] 
20. Vallabani, N.V.S.; Karakoti, A.S.; Singh, S. ATP-mediated intrinsic peroxidase-like activity of $\mathrm{Fe}_{3} \mathrm{O}_{4}$-based nanozyme: One step detection of blood glucose at physiological pH. Colloids Surf. B 2017, 153, 52-60. [CrossRef]

21. Singh, M.; Weerathunge, P.; Liyanage, P.D.; Mayes, E.; Ramanathan, R.; Bansal, V. Competitive Inhibition of the Enzyme-Mimic Activity of Gd-Based Nanorods toward Highly Specific Colorimetric Sensing of 1-Cysteine. Langmuir 2017, 33, 10006-10015. [CrossRef]

22. Li, W.; Zhi, X.; Yang, J.; Zhang, J.; Fu, Y. Colorimetric detection of cysteine and homocysteine based on an oligonucleotidestabilized Pd nanozyme. Anal. Methods 2016, 8, 5111-5116. [CrossRef]

23. Yang, Z.; Zhu, Y.; Nie, G.; Li, M.; Wang, C.; Lu, X. FeCo nanoparticles-embedded carbon nanofibers as robust peroxidase mimics for sensitive colorimetric detection of 1-cysteine. Dalton Trans. 2017, 46, 8942-8949. [CrossRef]

24. Ray, C.; Dutta, S.; Sarkar, S.; Sahoo, R.; Roy, A.; Pal, T. Intrinsic peroxidase-like activity of mesoporous nickel oxide for selective cysteine sensing. J. Mater. Chem. B 2014, 2, 6097-6105. [CrossRef]

25. Huang, Z.; Yang, Y.; Long, Y.; Zheng, H. A colorimetric method for cysteine determination based on the peroxidase-like activity of ficin. Anal. Methods 2018, 10, 2676-2680. [CrossRef]

26. Zou, H.; Yang, T.; Lan, J.; Huang, C. Use of the peroxidase mimetic activity of erythrocyte-like $\mathrm{Cu}_{1.8} \mathrm{~S}$ nanoparticles in the colorimetric determination of glutathione. Anal. Methods 2017, 9, 841-846. [CrossRef]

27. Ganganboina, A.B.; Doong, R.-A. The biomimic oxidase activity of layered $\mathrm{V}_{2} \mathrm{O}_{5}$ nanozyme for rapid and sensitive nanomolar detection of glutathione. Sens. Actuators B 2018, 273, 1179-1186. [CrossRef]

28. Nelson, D.L.; Cox, M.M. Lehninger: Principles of Biochemistry. In Priciples of Biochemistry, 7th ed.; Cox, M.M., Ed.; W. H. Freeman and Company: New York, NY, USA, 2017.

29. Walther, R.; Winther, A.K.; Fruergaard, A.S.; van den Akker, W.; Sørensen, L.; Nielsen, S.M.; Jarlstad Olesen, M.T.; Dai, Y.; Jeppesen, H.S.; Lamagni, P.; et al. Identification and Directed Development of Non-Organic Catalysts with Apparent Pan-Enzymatic Mimicry into Nanozymes for Efficient Prodrug Conversion. Angew. Chem. Int. Ed. 2019, 58, 278-282. [CrossRef]

30. Kang, T.; Kim, Y.G.; Kim, D.; Hyeon, T. Inorganic nanoparticles with enzyme-mimetic activities for biomedical applications. Coord. Chem. Rev. 2020, 403. [CrossRef]

31. Chen, W.; Li, S.; Wang, J.; Sun, K.; Si, Y. Metal and metal-oxide nanozymes: Bioenzymatic characteristics, catalytic mechanism, and eco-environmental applications. Nanoscale 2019, 11, 15783-15793. [CrossRef]

32. Xian, Z.; Zhang, L.; Yu, Y.; Lin, B.; Wang, Y.; Guo, M.; Cao, Y. Nanozyme based on $\mathrm{CoFe}_{2} \mathrm{O}_{4}$ modified with MoS 2 for colorimetric determination of cysteine and glutathione. Microchim. Acta 2021, 188, 65. [CrossRef] [PubMed]

33. Shrivastava, A.; Gupta, V. Methods for the determination of limit of detection and limit of quantitation of the analytical methods. Chron. Young Sci. 2011, 2. [CrossRef]

34. Luo, Y.; Duan, G.; Li, G. Synthesis and characterization of flower-like $\beta-\mathrm{Ni}(\mathrm{OH})_{2}$ nanoarchitectures. J. Solid State Chem. 2007, 180, 2149-2153. [CrossRef]

35. Kalam, A.; Al-Shihri, A.S.; Al-Sehemi, A.G.; Awwad, N.S.; Du, G.; Ahmad, T. Effect of pH on solvothermal synthesis of $\beta$-Ni(OH)2 and $\mathrm{NiO}$ nano-architectures: Surface area studies, optical properties and adsorption studies. Superlattice Microst. 2013, 55, 83-97. [CrossRef]

36. Parveen, N.; Cho, M.H. Self-Assembled 3D Flower-Like Nickel Hydroxide Nanostructures and Their Supercapacitor Applications. Sci. Rep. 2016, 6, 27318. [CrossRef]

37. Tong, G.-X.; Liu, F.-T.; Wu, W.-H.; Shen, J.-P.; Hu, X.; Liang, Y. Polymorphous $\alpha$-and $\beta$-Ni(OH) ${ }_{2}$ complex architectures: Morphological and phasal evolution mechanisms and enhanced catalytic activity as non-enzymatic glucose sensors. CrystEngComm 2012, 14, 5963-5973. [CrossRef]

38. Yang, L.-X.; Zhu, Y.-J.; Tong, H.; Liang, Z.-H.; Wang, W.-W. Hierarchical $\beta-\mathrm{Ni}(\mathrm{OH})_{2}$ and NiO carnations assembled from nanosheet building blocks. Cryst. Growth Des. 2007, 7, 2716-2719. [CrossRef]

39. Hall, D.S.; Lockwood, D.J.; Poirier, S.; Bock, C.; MacDougall, B.R. Raman and infrared spectroscopy of alpha and beta phases of thin nickel hydroxide films electrochemically formed on nickel. J. Phys. Chem. A 2012, 116, 6771-6784. [CrossRef] [PubMed]

40. Taşköprü, T.; Zor, M.; Turan, E. Structural characterization of nickel oxide/hydroxide nanosheets produced by CBD technique. Mater. Res. Bull. 2015, 70, 633-639. [CrossRef]

41. Mironova-Ulmane, N.; Kuzmin, A.; Steins, I.; Grabis, J.; Sildos, I.; Pärs, M. Raman scattering in nanosized nickel oxide NiO. J. Phys. Conf. Ser. 2007, 93. [CrossRef]

42. Yu, F.; Huang, Y.; Cole, A.J.; Yang, V.C. The artificial peroxidase activity of magnetic iron oxide nanoparticles and its application to glucose detection. Biomaterials 2009, 30, 4716-4722. [CrossRef] [PubMed]

43. Weerathunge, P.; Sharma, T.K.; Ramanathan, R.; Bansal, V. CHAPTER 23 Nanozyme-Based Environmental Monitoring. In Advanced Environmental Analysis: Applications of Nanomaterials; The Royal Society of Chemistry: London, UK, 2017; Volume 2, pp. 108-132.

44. Zhang, X.-Q.; Gong, S.-W.; Zhang, Y.; Yang, T.; Wang, C.-Y.; Gu, N. Prussian blue modified iron oxide magnetic nanoparticles and their high peroxidase-like activity. J. Mater. Chem. 2010, 20, 5110-5116. [CrossRef]

45. Zhang, W.; Hu, S.; Yin, J.-J.; He, W.; Lu, W.; Ma, M.; Gu, N.; Zhang, Y. Prussian Blue Nanoparticles as Multienzyme Mimetics and Reactive Oxygen Species Scavengers. J. Am. Chem. Soc. 2016, 138, 5860-5865. [CrossRef]

46. Wei, H.; Wang, E. Nanomaterials with enzyme-like characteristics (nanozymes): Next-generation artificial enzymes. Chem. Soc. Rev. 2013, 42, 6060-6093. [CrossRef] [PubMed] 
47. Wang, X.; Hu, Y.; Wei, H. Nanozymes in bionanotechnology: From sensing to therapeutics and beyond. Inorg. Chem. Front. 2016, 3, 41-60. [CrossRef]

48. Gao, L.; Zhuang, J.; Nie, L.; Zhang, J.; Zhang, Y.; Gu, N.; Wang, T.; Feng, J.; Yang, D.; Perrett, S.; et al. Intrinsic peroxidase-like activity of ferromagnetic nanoparticles. Nat. Nanotechnol. 2007, 2, 577-583. [CrossRef]

49. Chen, J.; Shu, Y.; Li, H.; Xu, Q.; Hu, X. Nickel metal-organic framework 2D nanosheets with enhanced peroxidase nanozyme activity for colorimetric detection of $\mathrm{H}_{2} \mathrm{O}_{2}$. Talanta 2018, 189, 254-261. [CrossRef] [PubMed]

50. Acker, M.G.; Auld, D.S. Considerations for the design and reporting of enzyme assays in high-throughput screening applications. Perspect. Sci. 2014, 1, 56-73. [CrossRef]

51. Robinson, P.K. Enzymes: Principles and biotechnological applications. Essays Biochem. 2015, 59, 1-41. [CrossRef]

52. Lopina, O.D. Enzyme Inhibitors and Activators; IntechOpen: London, UK, 2017. [CrossRef]

53. Sarkar, S.; Pradhan, M.; Sinha, A.K.; Basu, M.; Negishi, Y.; Pal, T. An Aminolytic Approach toward Hierarchical $\beta-\mathrm{Ni}(\mathrm{OH})_{2}$ Nanoporous Architectures: A Bimodal Forum for Photocatalytic and Surface-Enhanced Raman Scattering Activity. Inorg. Chem. 2010, 49, 8813-8827. [CrossRef]

54. Zhu, Z.; Wei, N.; Liu, H.; He, Z. Microwave-assisted hydrothermal synthesis of $\mathrm{Ni}(\mathrm{OH})_{2}$ architectures and their in situ thermal convention to NiO. Adv. Powder Technol. 2011, 22, 422-426. [CrossRef]

55. Li, C.; Zhang, H.; Gong, X.; Li, Q.; Zhao, X. Synthesis, characterization, and cytotoxicity assessment of N-acetyl-1-cysteine capped ZnO nanoparticles as camptothecin delivery system. Colloids Surf. B 2019, 174, 476-482. [CrossRef] [PubMed]

56. Pawlukojć, A.; Leciejewicz, J.; Ramirez-Cuesta, A.J.; Nowicka-Scheibe, J. L-Cysteine: Neutron spectroscopy, Raman, IR and ab initio study. Spectrochim. Acta A 2005, 61, 2474-2481. [CrossRef]

57. Strelow, J.; Dewe, W.; Iversen, P.W.; Brooks, H.B.; Radding, J.A.; McGee, J.; Weidner, J. Mechanism of action assays for enzymes. In Assay Guidance Manual; Markossian, S.S.G., Grossman, A., Eds.; Eli Lilly and Company: Indianapolis, IN, USA, 2012.

58. Luo, D.; Smith, S.W.; Anderson, B.D. Kinetics and Mechanism of the Reaction of Cysteine and Hydrogen Peroxide in Aqueous Solution. J. Pharm. Sci. 2005, 94, 304-316. [CrossRef] [PubMed] 